\title{
PENGARUH LATIHAN MENTAL IMAGERY TERHADAP HASIL TEMBAKAN ATLET MENEMBAK RIFLE JAWA BARAT
}

\author{
Satrio Anggoro Putra Wibowo, Nur Indri Rahayu \\ Program Studi Ilmu keolahragaan \\ Departemen Pendidikan Kesehatan dan Rekreasi \\ Fakultas Pendidikan Olahraga dan Kesehatan \\ Universitas Pendidikan Indonesia, Jl. Dr. Setiabudhi No. 299 Bandung \\ Email: satrioapw@gmail.com
}

\begin{abstract}
Abstrak
Mental Imagery adalah salah satu latihan mental yang sangat memiliki pengaruh untuk meningkatkan prestasi khususnya dalam menembak. Peneliti ingin membuktikan bahwa dengan latihan menggunakan mental Imagery dapat membuat peningkatan hasil tembakan yang signifikan. Tujuan penelitian ini untuk mengetahui pengaruh latihan dengan mental Imagery terhadap hasil tembakan atlet menembak. Metode penelitian yang digunakan adalah eksperimen one grup pretest-posttest. Sample penelitian berjumlah 10 orang atlet menembak air rifle Jawa Barat dengan teknik pengambilan sampling menggunakan teknik sampling purposive. Hasil penelitian ini dianalisi dengan bantuan spss ver.21 menunjukan data posttest $\mathrm{t}=-2,896$ dan sig. $=0,018<0,05$ maka Ho ditolak, artinya terdapat pengaruh yang signifikan (nyata) mental Imagery Training Terhadap Keterampilan Menembak Atlet Menembak Air Rifle. Kajian secara umum hasil penelitian latihan mental imagery akan mempengaruhi performa dan rasa percaya diri atlet menembak.
\end{abstract}

Kata kunci: mental Imagery training, menembak air rifle.

\section{PENDAHULUAN}

Keberhasilan seorang atlet menembak dalam mencapai prestasinya tidak terlepas dari kondisi mental atlet, karena mental merupakan bagian yang terpenting dalam olahraga menembak khususnya. Sesuai dengan yang diungkapkan (Komarudin, 2015 hlm. 3) bahwa "...selain melatih teknik, fisik, dan taktik yang sangat diperhatikan dalam olahraga adalah latihan mental...". Atlet perlu memiliki mental yang tangguh, sehingga dapat berlatih dan bertanding dengan semangat tinggi, dedikasi total, pantang menyerah, tidak mudah terganggu oleh masalah-masalah non-teknis atau pribadi. Pelatih memiliki peranan penting dalam memperhatikan latihan seorang atlet, khususnya latihan mental, karena masalah mental atlet sesungguhnya bukan murni masalah psikologis, namun faktor teknis atau fisiologis dapat menjadi penyebab terganggunya faktor mental. Oleh karena itu sebelum menerapkan latihan mental pada faktor mental psikologis, pelatih harus mengetahui terlebih dahulu penyebab dari 
masalah mental yang menjadi permasalahan atlet bersangkutan.

Pada umumnya banyak pelatih yang mengabaikan dan kurang memperhatikan aspek mental yang amat penting, karena selalu menekankan pada latihan penguasaan fisik, teknik, dan taktik. Sesuai dengan yang diungkapkan Harsono (1988) "para pelatih sering kali mengabaikan latihan mental atau kurang diperhatikan pada waktu melatih, oleh karena itu dalam mempersiapkan atletnya mereka selalu hanya menekankan pada penguasaan teknik, taktik serta pembentukan keterampilan (skills) yang sempurna". Pada akhir tahun 1970-an Amerika Serikat sudah menerapkan psikologis terkait dengan kebutuhan latihan mental dalam olahraga (http//www.wikipedia.com). Dasar pemikirannya adalah faktor yang berhubungan dengan penampilan sukses dalam pertandingan untuk mendapatkan hasil yang optimal sangat terkait erat dengan ketahanan mental atlet... (Komarudin, 2015 hlm. 3). Manusia terdiri dari kesatuan jiwa dan raga yang saling berdampingan satu sama lain atau yang disebut juga "psychosomatic unity" (Komarudin, 2015, hlm.1). Penampilan para atlet sebenarnya merupakan hasil gabungan dari beberapa faktor seperti kemampuan fisik, teknik, taktik atau strategi, dan mental. Latihan mental memegang peranan penting untuk menghasilkan prestasi yang optimal dikarenakan keadaan mental yang tangguh ketika menghadapi berbagai gangguan yang datang dari luar maupun dari dalam atlet agar dapat tetap menampilkan performa terbaiknya dan dapat tetap menjaga konsentrasi dengan baik. Itu semua memerlukan peranan penting psikologis agar dapat melakukan latihan mental dengan tujuan yang tepat. Beberapa contoh penerapan latihan dalam segi mental yang dapat digunakan untuk meningkatkan performa atlet seperti relaksasi, visualisasi, imagery, selft-hypnosis dan selft-talk merupakan macam-macam latihan yang mulai dikembangkan untuk latihan mental pada atlet dengan adanya ilmu psikologis tanpa mengabaikan keilmuan fisiologis dan permasalahan teknis pada cabang olahraga tertentu di dalamnya.

Menurut Cornelius Glenn C. Apfel (2002, hlm.1) atlet cabang olahraga menembak akan memiliki performa yang baik, apabila memiliki ketahanan fisik yang baik, juga memiliki ketenangan, ketahanan dan pengontrolan diri yang baik. Agar dapat menampilkan performa latihan maupun pertandingan dengan konsentrasi yang baik dan prestasi yang maksimal dengan penerapan latihan mental dengan penerapkan keilmuan psikologi di dalamnya yaitu salah satunya latihan mental dengan imagery.

Imagery merupakan salah satu teknik atau metode latihan keterampilan mental yang harus dikuasai oleh atlet. Latihan imagery terbukti memberikan manfaat kepada atlet untuk menciptakan kembali pengalaman gerak di dalam otaknya, sehingga atlet memungkinkan untuk menampilkan pola geak tersebut dengan baik. Prosesnya terjadi dengan mengingatingat pola gerak tersebut di dalam otaknya. Imagery sangat bermanfaat untuk meningkatkan kemampuan atlet, salah satunya untuk penguasaan keterampilan gerak olahraga, penguasaan strategi yang akan digunakan dalam pertandingan, mempersiapkan untuk tampil percaya diri, meningkatkan keterampilan interpersonal, dan mengendalikan gejala-gejala psikologis, konsentrasi, memperbaiki 
kesalahan, bahkan sangat bermanfaat untuk mempercepat pemulihan dari cedera yang dialami oleh atlet. Seperti yang dikatakan (Ari Setiatmoko 2013, hlm. 7) "latihan imagery (mental imagery) merupakan suatu bentuk latihan mental yang berupa pembayangan diri dan gerakan di dalam pikiran". Manfaat latihan tersebut dibuktikan oleh Nicklaus bahwa untuk sukses dalam memukul bola golf, sebelumnya ia latihan imagery dengan membayangkan pola gerak tersebut mulai mengayun sampai gerakan memukul bola. Atlet akan dapat melakukan latihan imagery untuk meningkatkan potensinya khususnya pada menembak apabila melakukan latihan imagery dengan sistematis. Itu dikuatkan dengan yang dikatakan Evans, Jones, dan Mullen (2004) dalam psikologi olahraga (komarudin 2013, hlm 88) “...bahwa seluruh atlet mempunyai potensi untuk meningkatkan kemampuan imagery mereka melalui latihan yang sistematis...." oleh karena itu penulis ingin mengetahui apakah terdapat pengaruh yang diberikan setelah latihan mental imagery yang dilakukan dengan pembayangan diri dan gerakan di dalam pikiran dengan membayangkan teknik menembak dengan benar yang dilihat terhadap performa tembakan atlet menembak Jawa Barat agar terbentuknya mental yang tangguh dalam menghadapi berbagai kejuaraan.

\section{METODE}

Metode penelitian ini menggunakan penelitian kuantitatif dengan pendekatan eksperiment, one group pretest posttest desingn. Menggunakan quasi eksperimen karena dalam penelitian ini sulit mendapatkan kelompok kontrol sebagai kelompok pembanding. Metode dalam penelitian ini juga merupakan rangkaian kegiatan percobaan dengan tujuan untuk menyelidiki suatu hal atau masalah sehingga diperoleh hasil dari proses treatment yang dilakukan pada sampel penelitian. Penelitian ini juga bertujuan untuk mencari pengaruh latihan mental imagery (variabel independen) terhadap hasil tembakan pada olahraga menembak (variabel dependen).

Setiap variabel dalam penelitian ini terdapat beberapa indikator yang menjadi aspek penilaian. Adapun indikator dari variabel imagery terdiri dari pengaruh yang didapat setelah diberikannya terhadap keterampilan teknik menembak sedangkan variabel dependen terdiri dari perbedaan skor hasil tembakan.

Populasi dalam penelitian ini seluruh atlet menembak rifle Jawa Barat yang terpilih kedalam tim platda sebanyak 20 orang. Adapun teknik sampling yang digunakan dalam penelitian ini adalah Purposive Sampling, dimana purposive sampling merupakan sampel yang diambil sesuai dengan pertimbangan-pertimbangan tertentu (sugiyono 2014, hlm. 85).

Sampel diambil sebanyak 10 orang atlet air rifle senior putra dan putri dengan teknik Purposive Sampling yang merupakan sampel yang diambil sesuai dengan pertimbangan-pertimbangan tertentu (sugiyono 2014, hlm. 85).

Adapun pertimbangan pertimbangan sampel yang diambil dalam penelitian ini adalah: a) sebagai atlet senior b) memahami dasar-dasar dan teknik olahraga menembak dengan baik c) memiliki pengalaman yang tinggi.

Instrumen yang digunakan dalam penelitian ini; Instrumen yang digunakan dalam penelitian adalah melakukan keterampilan menembak dengan tes skoring 
menembak menggunakan peraturan standart internasional. Dengan melakukan 60 tembakan untuk laki-laki dan 40 tembakan untuk wanita seperti yang dilakukan pada saat pertandingan yang sesungguhnya yaitu melakukan 10 tembakan pada setiap serinya untuk mengetahui nilai yang mampu dicapai atlet, menggunakan waktu 75 menit yang diberikan untuk laki-laki dan 60 menit untuk wanita. Yang di dapatkan dari peraturan internasional yang biasa digunakan pada kejuaraan ISSF (Internasional Shooting Sport Federation).

Alat-alat yang dibutuhkan dalam pengambilan data yakni: a) Lapangan tembak 10 meter; b) Senjata Air Rifle cal.177; c) Amunisi cal.177; d) Target sasaran senapan 10 meter; e) Score book; f) Stopwatch; g) ATK; h) Meja; i) Kursi.

\section{HASIL DAN PEMBAHASAN}

Pre test dan post test dilakukan dengan satu kali pengambilan data yang dilaksanakan di lapangan tembak cisangkan cimahi, pengambilan data post test dilakukan setelah sampel diberikan treatment mental imagery selama 20 kali pertemuan dengan 3 kali pertemuan disetiap pekannya. Treatment mental imagery diberikan pada setiap awal sesi latihan sebelum dilaksanakannya latihan teknik menembak.

Hasil pengambilan post test dan pre test treatment mental imagery dengan skoring menembak yang biasa digunakan pada event internasional, dapat dilihat pada Gambar 1 dan 2.

Pada Gambar 1. menunjukan bahwa adanya peningkatan skor atlet menembak air rifle putra dari awal pre test hingga post test setelah diberikan treatment mental imagery. Sedangkan pada Gambar 2. menunjukan bahwa adanya peningkatan skor atlet menembak air rifle putri dari awal pre test hingga post test setelah diberikan treatment mental imagery.

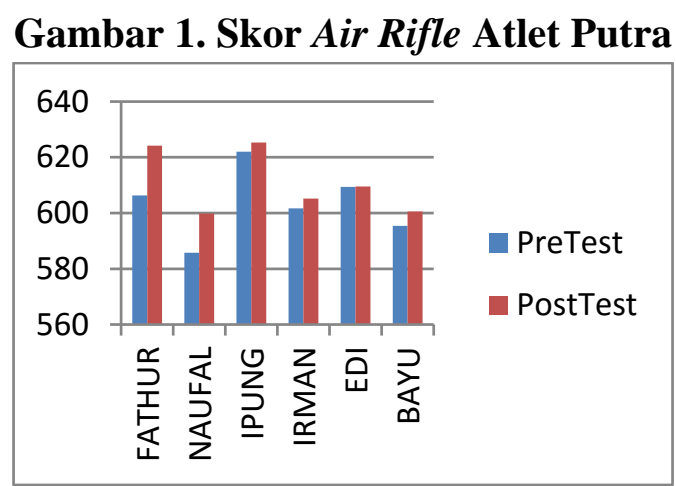

Gambar 2. Skor Air Rifle Atlet Putri

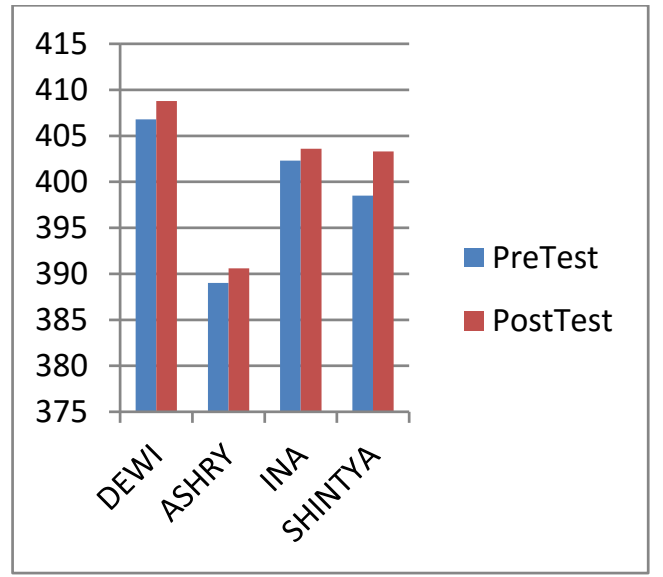

Gambar 3.

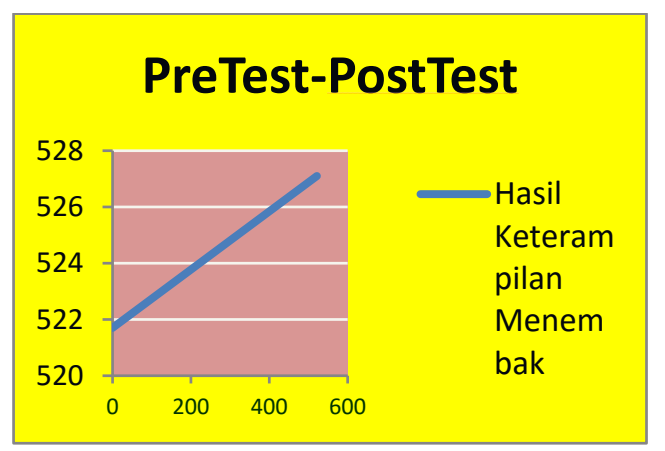

Berdasarkan Gambar 3 dilihat dari hasil pemberian treatment mental imagery terdapat peningkatan antara hasil pre test dan post test dengan nilai rata-rata pre test 521,72 dan nilai rata-rata post test 527,09. 
Tabel 1. Rata-rata dan Simpangan Baku

\begin{tabular}{|l|l|}
\hline Rata-rata & 527,09 \\
\hline Simpangan Baku & 108,45 \\
\hline
\end{tabular}

Berdasarkan hasil perhitungan rata-rata dan simpangan baku pada table 4.3 dan 4.4 adalah nilai rata-rata 527,09 dan simpangan baku 108,45 dari hasil post test yang didapat dari perlakuan latihan mental imagery yang diberikan kepada atlet menembak air rifle Jawa Barat mengalami peningkatan nilai hasil post test keterampilan menembak.

\section{Tabel 2. Pengujian Hipotesis}

\begin{tabular}{|l|l|l|l|}
\hline T & Sig & $\begin{array}{l}\text { Keputu } \\
\text { san }\end{array}$ & Kesimpulan \\
\hline$-2,896$ & 0,018 & $\begin{array}{l}\text { Ho } \\
\text { Ditolak }\end{array}$ & $\begin{array}{l}\text { Perbedaan } \\
\text { Signifikan }\end{array}$ \\
\hline
\end{tabular}

Terlihat bahwa nilai pada tabel diatas nilai $\mathrm{t}=-2,896, \mathrm{p}=0,018,0,05$ maka $\mathrm{Ho}$ ditolak, artinya terdapat perbedaan yang signifikan (nyata) antara latihan mental Imagery terhadap hasil tembakan.

Selain itu perbedaan juga dapat terlihat dari hasil penghitungan statistik nilai rata-rata 521,72 ketika posttest (sebelum diberikannya treatment) dan 527,09 ketika posttest (setelah diberikannya treatment). Dari data tersebut dapat disimpulkan bahwa hasil treatment latihan mental Imagery meningkatkan hasil tembakan atlet menembak.

Dari hasil penelitian yang dilakukan dapat menunjukan bahwa terdapat pengaruh pemberian perlakuan mental Imagery Training yang signifikan terhadap hasil keterampilan menembak atlet menembak Jawa Barat, itu dapat terlihat dari hasil tembakan yang dilakukan pada tes skoring yang dilaksanakan setelah adanya pemberian treatment mental Imagery Training. Hal ini menunjukan bahwa adanya pengaruh yang signifikan treatment mental Imagery Training dan latihan keterampilan menembak terhadap hasil tembakan yang dilakukan. Adanya pengaruh pemberian treatment latihan mental imagery diperkuat dengan hasil pengujian perbedaan antara sebelum diberikanya treatment dan sesudah diberikannya treatment memiliki perbedaan perolehan hasil dari melakukan keterampilan menembak.

Dari hasil posttest terdapat hasil yang mengalami peningkatan ada juga yang mengalami peningkatan tidak terlalu terligat, hal ini ditandai beberapa faktor seperti yang diungkapkan (Hidayat:2010) a. Latihan harus dilakukan dalam kondisi rileks, hal pertama yang mempengaruhi hasil posttest pada sampel salah satunya kurang rileks sampel pada saat melakukan latihan, sehingga mempengaruhi kepada fokus sampel, b. menggunakan seluruh indra, dari hal ini terdapat pengaruh yang sangat signifikan, sampel kurang fokus terhadap apa yang dibayangkan. Faktor lain yang dapat mempengaruhi kurang maksimalnya hasil yang diperoleh dari latihan mental imagery ini kurangnya kepercayaan terhadap dirinya sendiri jika dirinya dapat melakukan seperti apa yang ada di imajinasinya itu dapat berpengaruh pada suatu peristiwa dalam keadaan nyata, hal ini diperkuat dengan pernyataan (Garry dan Polascheck, 2000) dalam buku (Carole Wade, Carol Tavris 2007, hlm. 58) yang berjudul Psikologi edisi ke-9 menyatakan imajinasi aktif kita mendukung kepercayaan kita bahwa suatu peristiwa benar-benar terjadi. 
Latihan mental imagery yang dilakukan dalam penelitian ini adalah serangkaian aktifitas membayangkan dan memunculkan kembali aktifitas yang dilakukan dalam pikiran berupa peristiwa atau pengalaman gerak yang benar dan telah disimpan dalam ingatan. Karena dengan mengulang secara terus menerus dengan membayangkan aktifitas atau gerakan yang berada dalam pikiran dengan keadaan rileks dapat membuat seseorang menjadi semakin fokus dalam melakukan aktifitasnya dan dapat memprogram pikiran seseorang seperti yang diungkapkan Gian Sugiana (2013, hlm. 14) kata-kata yang kita ucapkan ataupun yang kita ucapkan secara berulangulang, akan menjadi sebuah program pikiran dalam pikiran anda. Oleh karena itu pengaruh yang signifikan dari latihan mental imagery ini dapat terlihat dalam penelitian ini. Hal ini sejalan dengan berbagai penelitian yang ada diantaranya Murphy, Jowdy dan Durtschi (1990) dalam Komarudin (2015 hlm. 87) melaporkan hasil penelitiannya yaitu: " $90 \%$ atlet olimpiade menggunakan bentuk latihan imagery, $97 \%$ atletnya merasa terbantu penampilannya, $94 \%$ atlet olimpiade melakukan imagery sebelum sesi latihan, $20 \%$ menggunakan imagery setiap sesi latihan. Calmels, et al., (2003); Cumming \& Hall, (2002) dalam Komarudin (2015, hlm. 88) menjelaskan secara keseluruhan atlet.

\section{KESIMPULAN}

Dalam olahraga menembak faktor mental menjadi sangat penting karena menembak merupakan cabang olahraga yang membutuhkan konsentrasi tinggi, sehingga apabila seorang atlet menembak memiliki mental yang kurang baik maka ketika atlet berlaga dalam suatu pertandingan dan mendapatkan gangguan mental baik dari lingkungan maupun dari diri atlet sendiri, maka untuk berlaga dalam suatu pertandingan atlet akan sulit untuk mendapatkan hasil yang maksimal. Dengan adanya latihan mental imagery yang diberikan kepada atlet menembak, akan membantu atlet suatu pertandingan untuk mendapatkan hasil yang maksimal, karena latihan mental imagery dapat membantu atlet untuk menjadi merasa lebih percaya diri, memiliki motivasi tinggi, dan meningkatkan tingkat konsentrasi untuk fokus dalam melakukan tembakan. Dengan kepercayaan yang dimiliki atlet ketika diberikan treatment imagery akan berdampak nyata untuk melakukannya dalam bentuk yang nyata.

Berdasarkan hasil penelitian yang dilakukan oleh penulis mengenai Pengaruh Latihan Mental Imagey Terhadap Hasil Tembakan Atlet Menembak Rifle Jawa Barat dapat disimpulkan beberapa aspek, Pertama, Terdapat pengaruh yang signifikan antara latihan mental imagery yang diberikan terhadap hasil tembakan atlet menembak Jawa Barat dengan nilai $t$ sebesar -2,896 dengan nilai signifikansi $0,018<0,05$ maka Ho ditolak; Kedua, Atlet menembak akan memiliki mental yang baik apabila diberikan latihan mental imagery karena atlet menembak akan memiliki kepercayaan diri dan motivasi tinggi yang dapat membantu membuat kondisi atlet untuk berkonsentrasi agar mendapatkan fokus yang baik.

Atlet menembak yang diberikan mental imagery akan mendapatkan dampak yang maksimal apabila perlakuan yang diberikan dilakukan dengan rasa kepercayaan untuk melakukan dalam tindak nyata. 


\section{DAFTAR PUSTAKA}

Adang Suherman, Nur Indri Rahayu. (2014). Modul Statistika untuk ILMU KEOLAHRAGAAN. Bandung

Ari Setiatmoko. (2013). Latihan Mental Bagi Atlet elit. Bandung: Artikel.

Arikunto, S. (2013). Prosedur Penelitian Suatu Pendekatan Praktik. Jakarta: Rineka Cipta.

Cornelius Glenn C. Apfel. (2006). Pengenalan Tentang Disiplin Menembak. Bali.

Darwitos. (2011). Latihan Memprogram Pikiran. (online): tersedia: http://ajaibnyapikirankita.blogspot.co.id/2011/07/tips-singkat-cara-sederhanamemprogram.html

Hidayat, Y. (2010). Imajeri Mental dan Keterampilan Motorik (Studi Meta analisis). Jurnal olahraga prestasi.

International Shooting Sport Federation. (2014). Rifle Rules. Munich.

Komarudin. (2015). Psikologi Olahraga edisi revisi: Latihan Keterampilan Mental dalam Olahraga Kompetitif. Bandung: PT Remaja Rosdakarya

Sugiyono. (2014). Metode Penelitian Kuantitatif kualitatif dan R\&D. Bandung: ALFABETA, CV

W Arya Purwadari. (2013). sistem pembinaan dengan model High Performance Program yang dilakukan melalui Sport Science, Technical Coach, serta program strength and conditioning.

Semarang: skripsi.

Tersedia: http://eprints.undip.ac.id/42608/1/Document1.pdf 